\title{
A study of an influence of a fiber arrangement of a laminate ply on the distribution and values of stresses in the multi-layered composite material
}

\author{
Krzysztof Herbuś* and Piotr Ociepka \\ Institute of Engineering Processes Automation and Integrated Manufacturing Systems, Faculty of \\ Mechanical Engineering, Silesian University of Technology, Konarskiego 18a, 44-100 Gliwice, \\ Poland
}

\begin{abstract}
In the work are presented studies related with the influence of a fiber arrangement of a laminate ply on the distribution and values of stresses in the multi-layered composite material. For this purpose, the characteristics of the three-point bending test, according to the standard PN-EN ISO 7438, of specimens made from the composite material, where a single ply is a composition of epoxy resin and glass fibres, was mapped. The modelling process of the multi-layered composite material and its strength verification was performed in the PLM Siemens NX system. Based on the results of performed numerical studies, the relation between the value of the main angle of an arrangement of fibers in each plies of the laminate, and the distribution and values of stresses, occurring in the examined specimens has been determined.
\end{abstract}

\section{Introduction}

In recent years, a significant increase in the use of composite materials in engineering applications has been observed. One of the main groups of composite materials is multilayer composite materials. These materials are characterized by a distinctive structure within which the matrix and reinforcement can be distinguished. As the matrix material could be used a variety of resins that are intended to assemble the reinforcing layers. Hence one of the basic forms of matrix reinforcement is the use of different types of fibres. The reinforcement in the form of a fibre can take the form of a rowing where all the reinforcement fibres are laid in the same direction or a fabric in case the reinforcement fibres are woven in accordance with the determined weave. Reinforcement can also be discontinuous when it is in the form of staple fibres. Due to the continuous expansion of the areas of application of multilayer composite materials, research is conducted to determine their correct modelling [1-3] and verification through a virtual experiment using the computer-aided approach.

The modern systems of the CAD/CAE class enable conducting researches concerning the kinematic, dynamic, and MES analysis [4-17]. The paper presents computer aided researches on the influence of fibres orientation of a laminate layer on the distribution and values of stresses in a multi-layered composite material. Virtual tests were conducted in accordance

* Corresponding author: krzysztof.herbus@polsl.pl 
with the recommendations of PN-EN ISO 7438. This standard refers to a three-point test of sample bending. In Figure 1 is shown the accepted scheme of the three-point test of composite samples bending reinforcement with glass fibres. According to the standard, the ratio of support spacing to the height of the tested sample should be equal to 16 .

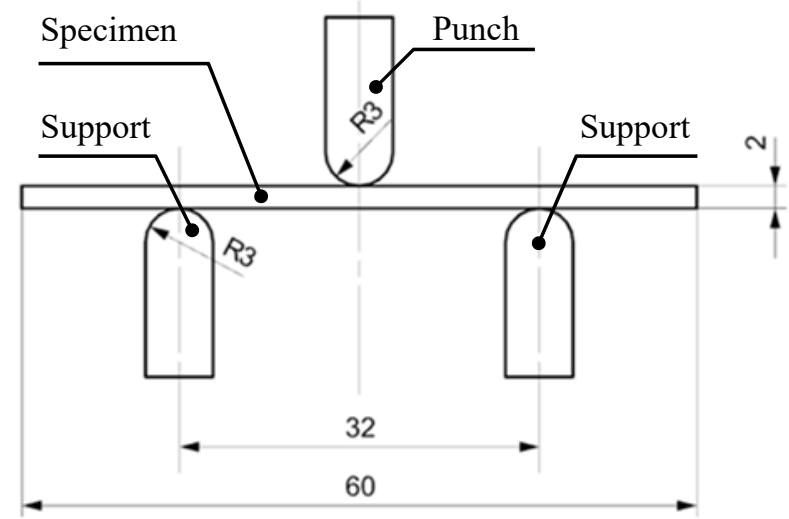

Fig. 1. The scheme of the three-point bending test.

In the accepted scheme of supporting and loading of the tested sample there are two fixed supports with a spacing of $32 \mathrm{~mm}$ and a punch that can move only in the vertical axis. The punch acts on the composite sample in the middle of its length. The tested sample has the following dimensions: length $60 \mathrm{~mm}$, height $2 \mathrm{~mm}$, width $10 \mathrm{~mm}$.

\section{A structure of the used composite material}

The structure of the sample subjected to the cycle of virtual experiments consists of four layers. Each layer is a composition of epoxy resin and fiberglass. The used fiberglass reinforcement is in the form of a fabric. Within the fabric, the fibres of weft and warp are weaved, relative to each other, at the angle of $90^{\circ}$ (Figure 2). In the created composite material the main direction of fibres orientation is determined according to the $\mathrm{Y}$ axis of the absolute coordinate system. The method of laying the following composite layers was defined, as being consistent with the direction of the $\mathrm{Z}$ axis. It was assumed that the layer 1 is the layer that directly contacts with the punch and the layer 4 is the layer that directly comes into contact with the supports. The other two layers are laid between them. Because of the nature of the carried out analyses, an important parameter is the principal angle of alignment of the fibres $(\theta)$ within the composition of a composite material. This angle is defined as the angle between the $\mathrm{Y}$ axis of the absolute coordinate system and the direction of the fabric weft.

To conduct the numerical tests, using the FEM method, it was implemented the presented structure of composite material in the PLM Siemens NX 10 program (Figure 2). The applied epoxy resin has the following basic properties: mass density $1300\left[\mathrm{~kg} / \mathrm{m}^{\wedge} 3\right]$, Young's modulus 3000 [MPa], Poisson's ratio 0.37 . Whereas the used glass fibres have the following basic features: mass density 2540 [kg/m^3], Young's modulus 70000 [MPa], Poisson's ratio 0.2 . 


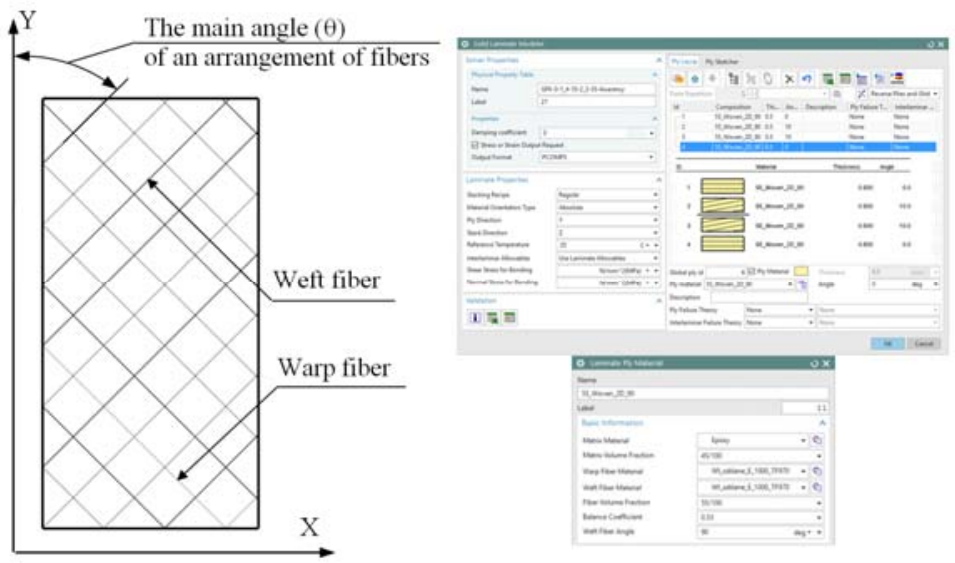

Fig. 2. Definition of the structure of the composite material.

One layer of the composite material has the following properties: matrix material - epoxy, matrix volume fraction -0.45 , warp fiber material - glass fiber, weft fiber material - glass fiber, fiber volume fraction -0.55 , balance coefficient -0.53 , weft fiber angle -90 degrees, Young's modulus $1-24250$ [MPa], Young's modulus $2-22230$ [MPa], Young's modulus 3 - 3000 [MPa], Poisson's ratio $12-0.079$, Poisson's ratio $13-0.32$, Poisson's ratio $23-0.326$, shear modulus $12-2329$ [MPa], shear modulus $13-1118$ [MPa], shear modulus $23-1443$ $[\mathrm{MPa}]$, mass density $-1982\left[\mathrm{~kg} / \mathrm{m}^{\wedge} 3\right]$, thickness $-0.5[\mathrm{~mm}]$.

\section{FEM analysis of the three-point bending of specimens}

To model the form of displacement of the analysed composite sample during the three-point bending test, a model for FEM was prepared. This model includes the following types of boundary conditions: fixed constraint, surface-to-surface contact, enforced displacement constraint.

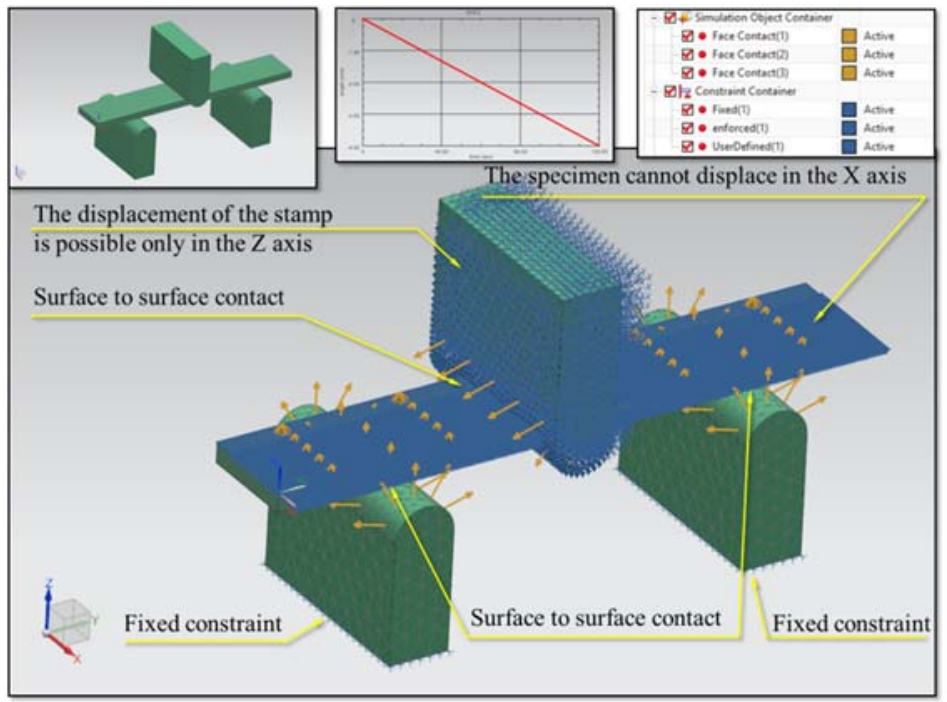

Fig. 3. The model prepared to the FEM analysis. 
The model also includes an input force in the form of the punch displacement at the speed of $2 \mathrm{~mm} / \mathrm{min}$. This displacement was only possible along the $\mathrm{Z}$ axis of an absolute coordinate system.

The first series of numerical tests was carried out assuming that all the layers of the composite material composition had the same principal angular position of the fibres relative to the absolute coordinate system. The stress distribution, in this case, changes constantly up to the angle of $\theta=45^{\circ}$. When this value is exceeded, the obtained stress distribution is a mirror image with respect to the previous (Figure 4). This is because the impact factor equal to 0.5 is considered.

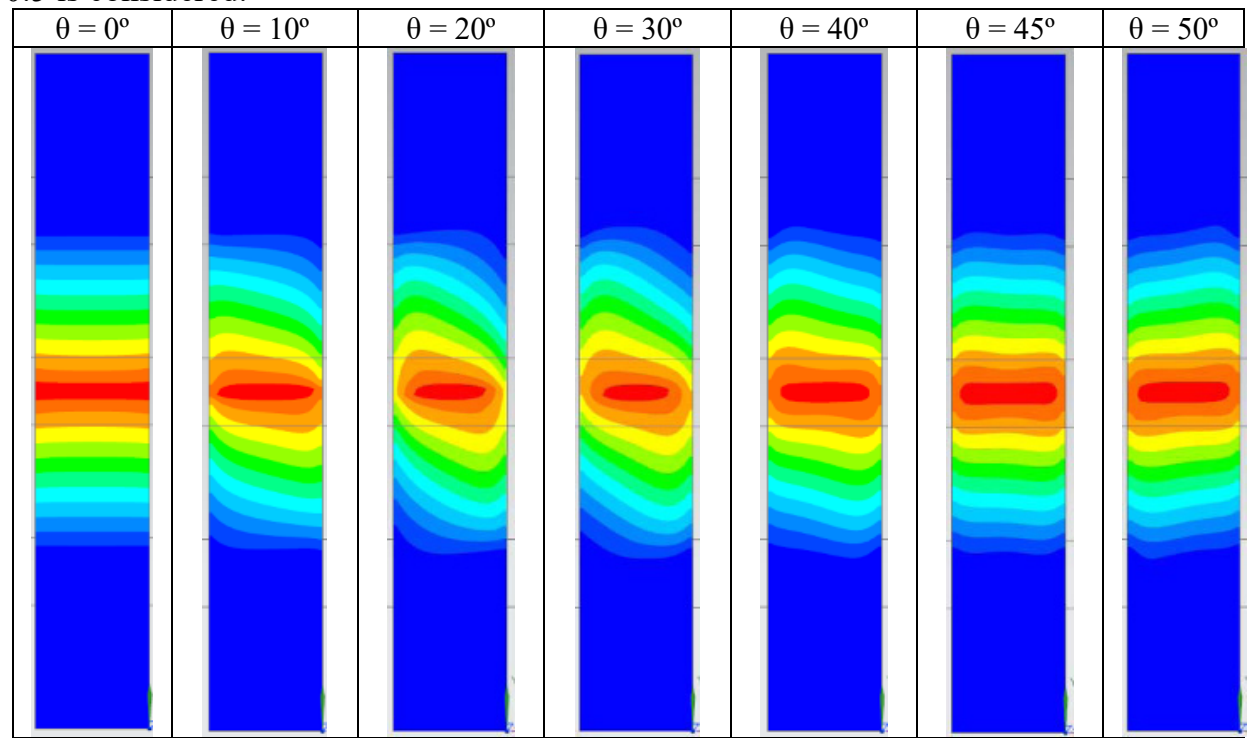

Fig. 4. Distribution of stresses depending on the angle of an arrangement of the ply (ply1)

In the Figure 5 is shown a graph presenting the relationship between the angle $\theta$ and the maximum values of reduced stresses in the particular layers of the composite material. It could be seen that as the angle $\theta$ increases up to $45^{\circ}$, the maximal values of reduced stresses in all layers are decreasing.

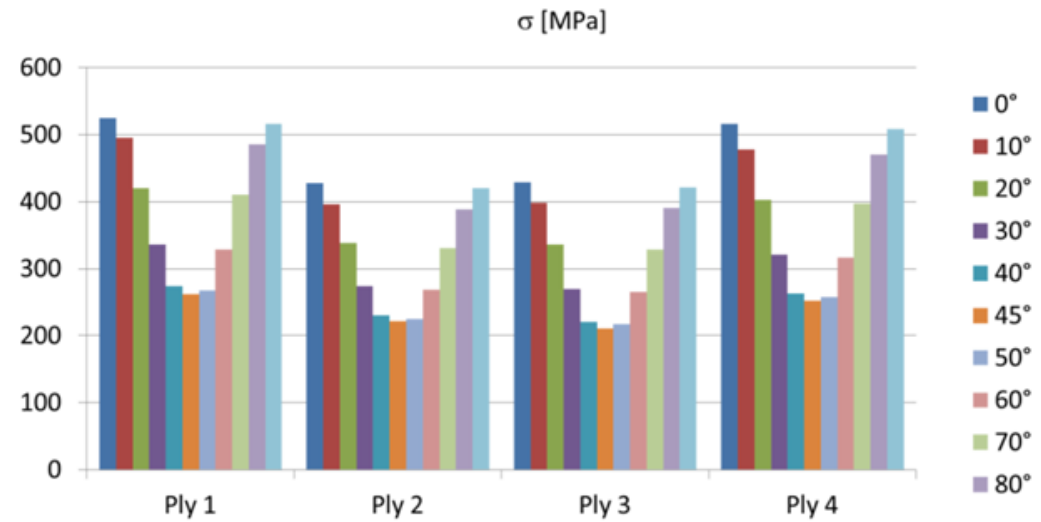

Fig. 5. The values of reduced stresses depending on the angle of an arrangement of the ply (all the plies arranged in the same way). 
The next cycle of the numerical tests was conducted with the assumption that the angle $\theta$ with respect to the layers 1 and 4 is unchanged, while the angle $\theta$ with respect to the layers 2 and 3 varies at the same time between 0 and $90^{\circ}$ (Figure 6a).

In this case are observed: a significant decrease of stresses in layers 2 and 3 and an increase in stress values in layers 1 and 4.
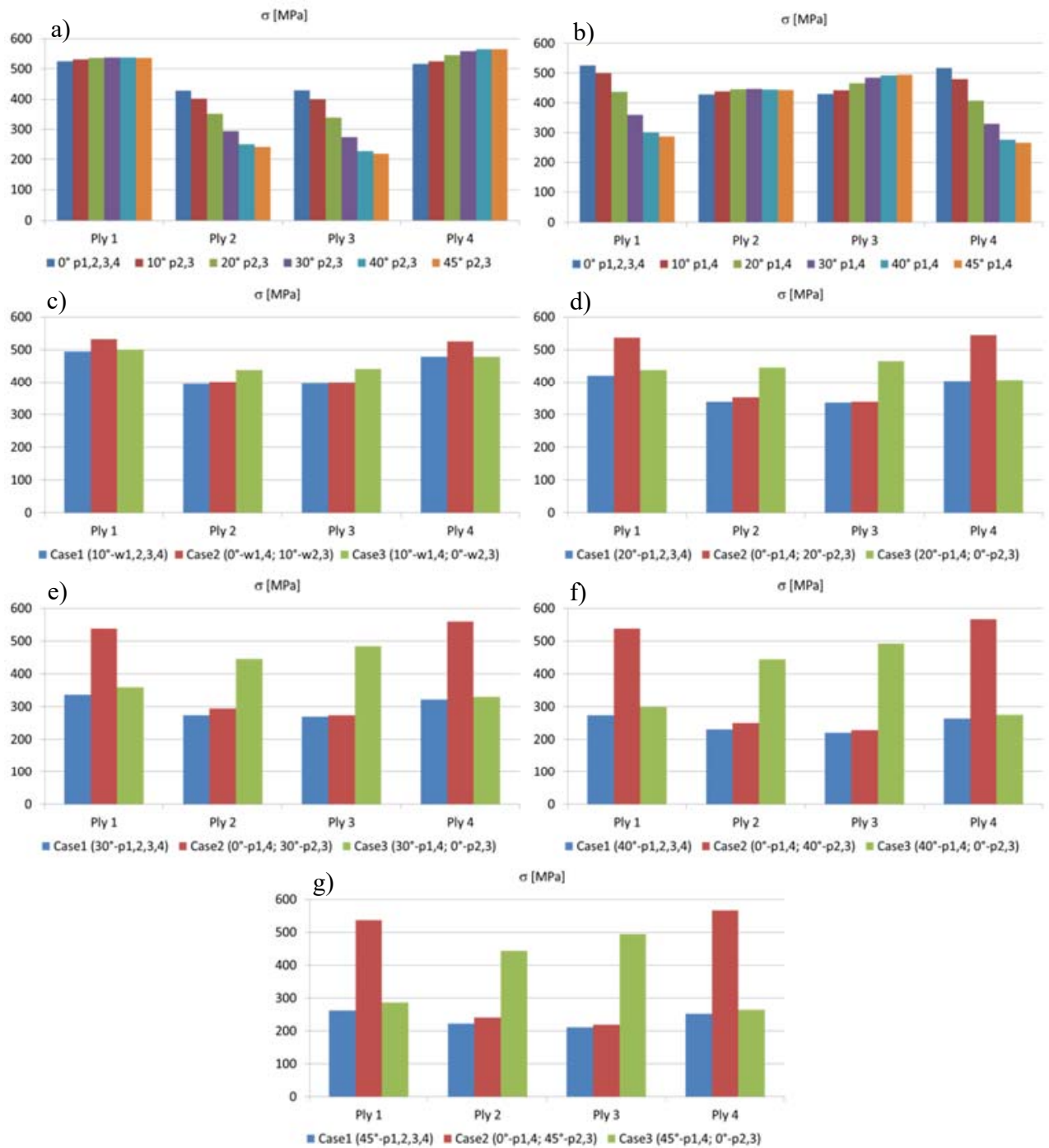

Fig. 6. The values of reduced stresses depending on the angle of an arrangement of the ply (the plies arranged in the differently way).

The last cycle of numerical tests was carried out basing on the assumption that the angle $\theta$ with respect to the layers 2 and 3 is unchanged while the angle $\theta$ with the respect to the layers 1 and 4 changes simultaneously between 0 and $90^{\circ}$ (Figure 6b).

In this case are observed: a large decrease in stress values in layers 1 and 4 and an increase in stress values in layers 2 and 3. In Figures from $6 \mathrm{c}$ to $6 \mathrm{~g}$ are shown summaries of the results obtained in these three cycles of tests to illustrate the effect of the change of the main angle of fibres orientation $\theta$ on stress values occurring in particular layers of the composite material. 


\section{Conclusions}

The change of the angle of the fibres orientation causes the change of the stress distribution in particular layers of the composite material. If all layers of a composite material are uniformly oriented (have the same angle), the most uniform stress distribution, in the individual layers of the composite, is obtained. With the increasing difference of the angle of layers orientation in the composite material, could be observed greater differences between the stress values in the individual layers of a composite material.

The created FEM model allows virtual conducting the three-point bending of samples with respect to any fibre-reinforced composite material. It should be stressed, however, that the created model allows determining the relationship between stress values in individual layers of multilayer composite materials and the angle $\theta$, only in terms of its nature or tendency. To determine the exact relationship between the stress values and the angle $\theta$, the FEM model should be fitted to the real object.

\section{References}

1. R. Martinsa, L. Reisa, R. Marat-Mendesa, Procedia Structural Integrity, 1, 066-073 (2016)

2. P. Folega, Journal Of Vibroengineering, 17, 155-163 (2015)

3. W. Cecot, M. Oleksy, Computers and Mathematics with Applications, 70, 1391-1400 (2015)

4. W. Banaś, K. Herbuś, G. Kost, A. Nierychlok, P. Ociepka, D. Reclik, Advanced Materials Research, 837, 537-542 (2014)

5. K. Foit, G. Ćwikła, MATEC Web of Conferences 94, UNSP 05002 (2017)

6. A. Gwiazda, Advanced Materials Research, 837, 393-398 (2014)

7. A. Gwiazda, Applied Mechanics and Materials, 474, 417-422 (2014)

8. K. Herbuś, P. Ociepka, IOP Conf. Series: Materials Science and Engineering, 95, 012096 (2015)

9. A. Dymarek, T. Dzitkowski, K. Herbuś, G. Kost, P. Ociepka, Advanced Materials Research, 837, 351-356 (2014)

10. P. Ociepka, K. Herbuś, IOP Conf. Series: Materials Science and Engineering, 95, 012101 (2015)

11. K. Herbuś, P. Ociepka, IOP Conf. Series: Materials Science and Engineering, 95, 012084 (2015)

12. P. Ociepka, K. Herbuś, IOP Conf. Series: Materials Science and Engineering, 95, 012100 (2015)

13. K. Herbuś, P. Ociepka, IOP Conf. Series: Materials Science and Engineering, 145, 042018 (2016)

14. K. Herbuś, P. Ociepka, IOP Conf. Series: Materials Science and Engineering, 145, 052010 (2016)

15. A. Buchacz, A. Baier, K. Herbuś, M. Majzner, P. Ociepka, Applied Mechanics \& Materials, 809/810, 944-949 (2015)

16. A. Buchacz, A. Baier, J. Świder, M. Płaczek, A. Wróbel, K. Herbuś, P. Ociepka, W. Banaś, M. Sobek, Ł. Grabowski, M. Majzner, Analytical and experimental tests and determination of characteristics of components working as assemblies of innovative structures of repaired freight cars (Wydawnictwo Politechniki Śląskiej, Gliwice 2016)

17. A. Buchacz, A. Baier, K. Herbuś, M. Majzner, P. Ociepka, Springer Proceedings in Mathematics \& Statistics, Dynamical Systems: Modelling, 181, 97-105, (2016) 